\title{
A COMBINING GENETIC LEARNING ALGORITHM AND RISK MATRIX MODEL USING IN OPTIMAL PRODUCTION PROGRAM
}

\author{
Dr Mirjana Misita \\ University of Belgrade, Faculty of Mechanical Engineering, Belgrade, Serbia \\ Dr Galal Senussia * \\ Omar El-Mohktar University, Industrial Engineering Department, El-Baitha, Libya \\ MSc Marija Milovanović \\ University of Belgrade, Faculty of Mechanical Engineering, Belgrade, Serbia
}

One of the important issues for any enterprises is the compromise optimal solution between inverse of multi objective functions. The prediction of the production cost and/or profit per unit of a product and deal with two obverse functions at same time can be extremely difficult, especially if there is a lot of conflict information about production parameters. But the most important is how much risk of this compromise solution. For this reason, the research intrduce and developed a strong and cabable model of genatic algorithim combinding with risk mamagement mtrix to increase the quality of decisions as it is based on quantitive indicators, not on qualititive evaluation. Research results show that integration of genetic algorithim and risk mamagement matrix model has strong significant in the decision making where it power and time to make the right decesion and improve the quality of the decision making as well.

Key words: Multi-objective function, Genetic Algorithim, Risk Management, Optimum Production Program, Matrix, Costs

\section{INTRODUCTION}

The analysis of the production program of enterprises is an important and complex segment of managing the enterprise, considering the fact that it influences all elements or resources, such as planning of the material, human resources, machinery resources, research and development, marketing etc. All of these resources influence in multi-criteria optimization of production program. To reduce and improve the decesion making quality, it is important and necessary to evaluate them to minimize the risk of operating losses.

In investigations carried out to date the production program optimization was based on multicriteria approach using linear functions [01, 09]. Using nonlinear functions in multi-objective optimization enables the application of genetic algorithms and is a step forward in the analysis of the product optimal quantities to maximize production resources utilization [06, 10, 07]. On the other hand, economic calculation of the product cost price is a complex procedure, so that the analysis of optimal production program most commonly employed direct costs to determine the cost price and to define the cost function. However, cost functions based only on product variable costs cannot provide real optimal product quantities but are more suitable for ranking products that should be given priority in manufacturing. Introducing overhead costs in the function of cost price is a complex calculation procedure most often difficult to understand by the user in a concrete enterprise, considering that it is not easy to classify individual expenses. It is thought that in metalworking companies, roughly assessing, direct costs account for about $60 \%$ of total unit costs, while the share of overhead costs is $40 \%$ [03].

In business of enterprises, there are several categories of risk: risk of equipment failure (estimated in relation to human safety, to evironment, to business losses, ect.), risk management as a security measure, finacial risk assessment in cases of loan approval, quality management risk, ect. Generally, Enterprise Risk Management is relatively new concept, Fraser and Simskins [05] distinguish following risk categories: Shareholder 
value risk, Financial reporting risk, Governance risk, Customer and market risk, Operations risk, Innovation risk, Brand risk, Partnering risk, Communications risk.

Risk management consisit of strategic risk, operational risk, financial risk and risk acceptance. Strategic risk deal with competition, market position and economic conditions. Operational risk
Concerned with the daily operations, precisely, to the consequences of daily decisions made in the company. The financial risks are related to relations with banks and stockholders, etc. The types of risk and process steps itroduced by Risk Management Committee 2003 [11].

Table 1: Enterprise Risk Management [8]

\begin{tabular}{|c|c|c|c|c|}
\hline \multicolumn{5}{|c|}{ ERM Framework } \\
\hline \multirow{2}{*}{ Process steps } & \multicolumn{4}{|c|}{ Type of risk } \\
\hline & Hazard & Financial & Operational & Strategic \\
\hline \multicolumn{5}{|l|}{ Establish Context } \\
\hline \multicolumn{5}{|l|}{ Identify risk } \\
\hline \multicolumn{5}{|l|}{ Analyze / quantify risks } \\
\hline \multicolumn{5}{|l|}{ Integrate risk } \\
\hline \multicolumn{5}{|l|}{ Assess / Prioritize Risks } \\
\hline Treat / Exploit Risks & & & & \\
\hline
\end{tabular}

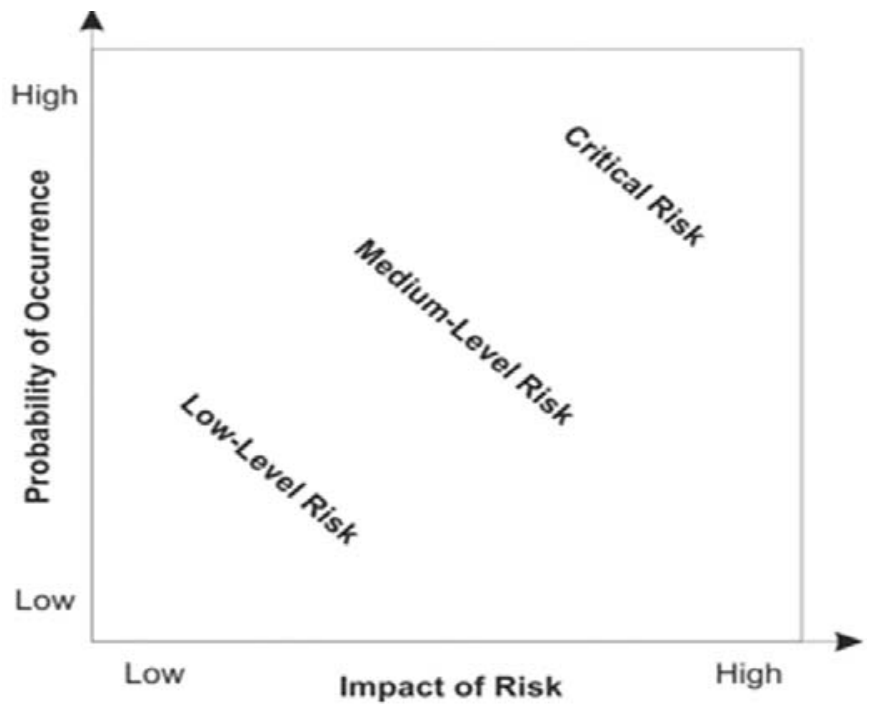

Figure 1: Risk Impact/Probability Chart

The risk is defined as product of probability and consequence of certain events, which can be expressed in formula:

$R=P^{*} Q$

$P$ - Probability a particular event.

$Q$ - Consequences of particular event.

For any enterprises, there are external and internal of n-sources of risk. The total risk will represented by high-risk, medium-risk and low-risk sources of operating losses.

$$
R_{i}=\left\{R_{\text {high }}, R_{\text {medium }}, R_{\text {low }}\right\}, \quad i=1,2, \ldots n
$$

The based approach of applying risk are risk identification - what can affect the implementation of production program, risk analysis - defining the probability of occurrence of that, and risk assessment - determining the consequences, expressed in the form of operating losses. The most low-risk sources of operating losses refer to good quality decision. Figure 2 shows the map for identifying Business risks.

Glover at all [9] states that the most real life optimization and scheduling problems are too complex to be solved completely and that the complexity of real life problems often exceeds the 
ability of classic methods. Miettinen [08] considered that a key challenge in the real-life design is to simultaneously optimize different objectives through taking into account different criteria low cost, manufacturability, long life and good performance, which cannot be satisfied at the same time.

Profit maximization is the main objective of business enterprises and as such the subject of numerous investigations. Profit is defined as the difference between the total revenue generated by selling products on the market and the overall costs, i.e.:

$P=T R-T C$

Where:

$P$ - Total profit

$T R$ - Total revenue

$T C$ - Total cost

When analyzing the possibilities of profit maximization, it is important to consider the fluctuation of the TR and the TC. The TR depends on supply and market demands for particular types of goods, while the TC depends on different constraints faced by the company, such as the mechanical facilities, number and structure of employees, possibility of providing necessary specific materials for the manufacturing process implementation, delivery etc. For the company, to be competitive on the market means to produce a product at an appropriate price and quantity with the use of capital and labor in the appropriate volume and costs. Therefore, profit maximization refers to the optimization of variable parameters in the observed model, with given production constraints.

$$
\operatorname{Max} \mathrm{P}=\sum_{i=1}^{n} Q\left(W_{p i}-W_{v i}\right)-T_{c}
$$

Where:

$P$ - Profit

$Q-$ Quantity of product

$W_{\text {pi }}$ - Selling price of the ith product

$W_{v i}^{p i}-$ Variable cost of the ith product

$T_{c}-$ Constant cost

In real life, the functions of dependence of production quantity and the TR and the TC are nonlinear. The maximum profit is the maximum difference between the total profit curve and the total cost curve, as represented in the Figure 3.

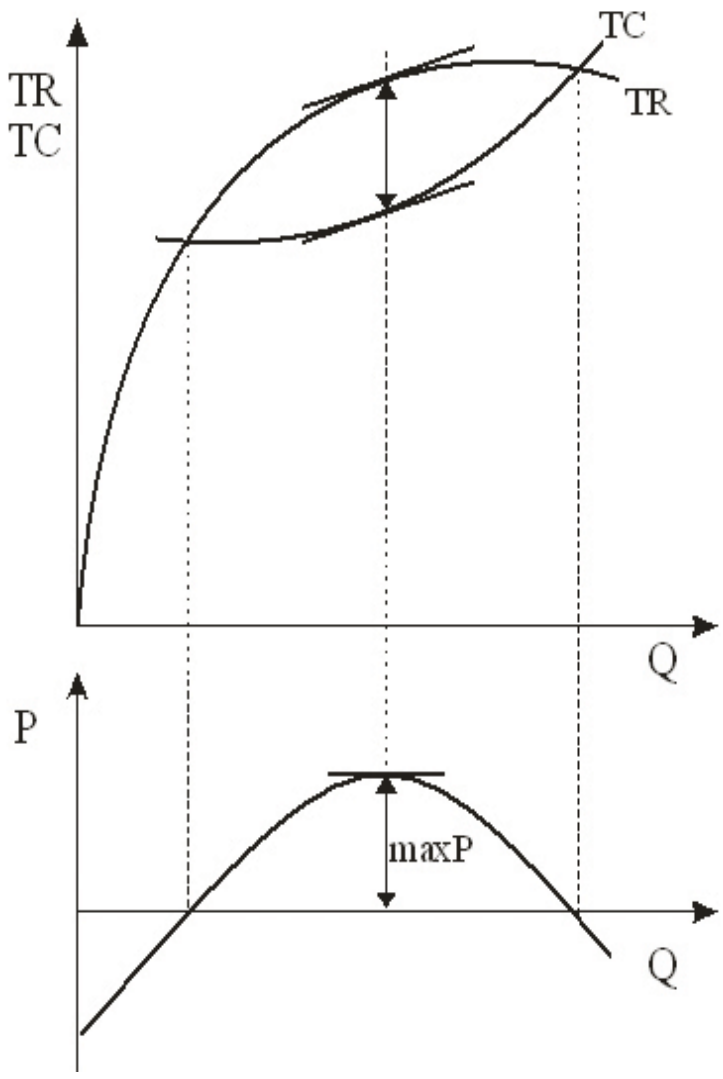

Figure 2: Graphic representation of profit maximization

In real enterprise's operating conditions the functions of the TR and the TC are nonlinear and to determine them two different approaches must be applied.

The TR function consists of the sum of variable and fixed costs, therefore, the sum of linear mathematical form by applying the Lagrange interpolation polynomial based on the values of variable costs from the previous period.

It is possible to determine the nonlinear function of fixed costs in a Lagrange interpolation polynomial is, in our case, a function of production quantity $P(Q)$ with $\leq(n-1)$ level if we have $n$ data points on the value of costs from the previous period.

$$
P(Q)=\sum_{j=1}^{n} P_{j}(Q)
$$

Where:

$$
P_{j}(Q)=y_{j} \prod_{\substack{k=1 \\ k \neq j}}^{n} \frac{Q-Q_{k}}{Q_{j}-Q_{k}}
$$




\section{METHODOLOGY}

Methodological steps in developing model for risk management integration methodology and GA is shown on Figure 3.

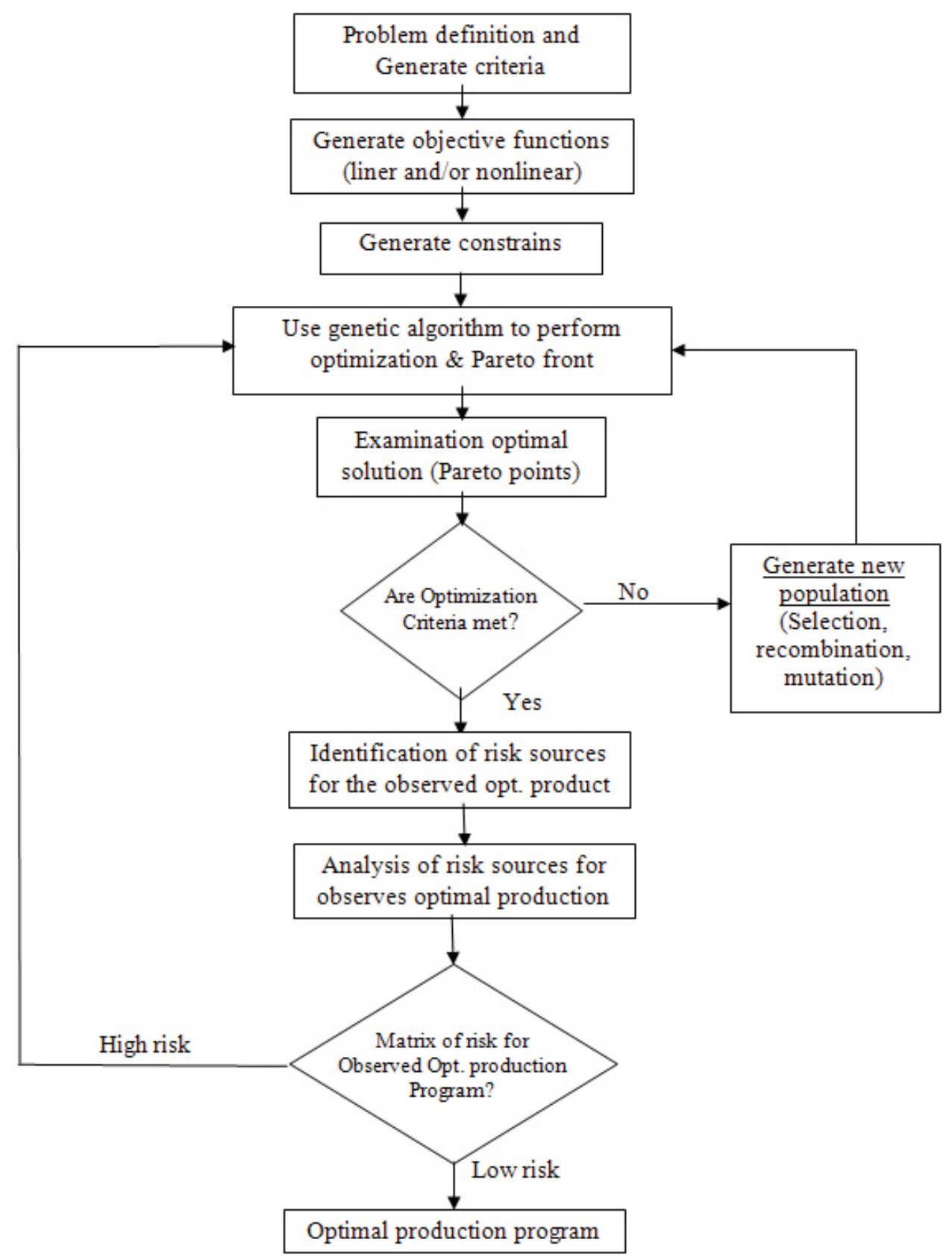

Figure 3: Steps in developing model for risk management integration methodology and GA

\section{CASE STUDY}

In the company engaged in manufacturing precision measuring instruments, we have analyzed the available data and formed nonlinear functions of the TR and the TC for the three products:

a) Clocks

Revenue function:

$f(x)_{11}=T R(Q)=-0.04 Q^{2}+686 Q-1375.3$
Cost function:

$f(x)_{21}=T C(Q)=-0.024 Q^{2}+410 . Q-4342$

b) Water meter

Revenue function:

$f(x)_{12}=T R(Q)=-0.18 Q^{2}+4298 Q-343884$

Cost function:

$f(x)_{22}=T C(Q)=-0.49 Q^{2}+3382.4 Q-463764$ 
c) Gas meter

Revenue function:

$f(x)_{13}=T R(Q)=-0.87 Q^{2}+5984.5 Q-5715.1$

Cost function:

$f(x)_{23}=T C(Q)=-0.58 Q^{2}+3818.2 Q-3643.6$
The functions of criteria for profit maximization will have the form:

$$
\begin{aligned}
& \max f(x)=\sum_{i=1}^{3} f_{1 i}=f(x)_{11}+f(x)_{12}+f(x)_{13} \\
& \min f(x)=\sum_{i=1}^{3} f_{2 i}=f(x)_{21}+f(x)_{22}+f(x)_{23}
\end{aligned}
$$

Table 2: Evaluation of risk sources and determination of trend

\begin{tabular}{|l|c|c|c|}
\hline Risk Source & $\begin{array}{c}\text { Risk rating } \\
\mathbf{1}^{\text {st }} \mathbf{Q . 2 0 1 0}\end{array}$ & $\begin{array}{c}\text { Risk } \\
\mathbf{2}^{\text {nd }} \mathbf{Q} \text {. 2010 }\end{array}$ & $\begin{array}{c}\text { Risk } \\
\mathbf{3}^{\text {rd }} \mathbf{Q} \text {. 2010 }\end{array}$ \\
\hline \hline Operation cost. & Low & Medium & Medium \\
\hline \hline Labor cost & Low & Medium & Medium \\
\hline Lubricant cost & Low & Low & Low \\
\hline Raw martial cost & Medium & High & High \\
\hline Fixed cost & Medium & Medium & Medium \\
\hline capital availability & Medium & Medium & Medium \\
\hline $\begin{array}{l}\text { business operations } \\
\text { supply chain management }\end{array}$ & Medium & Medium & Medium \\
\hline information technology & Medium & High & High \\
\hline planning & Medium & Medium & High \\
\hline \hline reporting & Low & Medium & Medium \\
\hline
\end{tabular}

Respectively:

$f(1)=-0.04 * x(1)^{\wedge} 2+686^{*} \times(1)-0.18 * x(2)^{\wedge} 2+$

$4298 * \mathrm{x}(2)-0.87 * \mathrm{x}(3)^{\wedge} 2+5984.5 * \mathrm{x}(3)-350975.4$;

$\mathrm{f}(2)=-0.024 * \mathrm{x}(1)^{\wedge} 2+410^{*} \mathrm{x}(1)-0.49^{*} \mathrm{x}(2)^{\wedge} 2+$

$3382.4 * \mathrm{x}(2)-0.58 * \mathrm{x}(3)^{\wedge} 2+3818.2 * \mathrm{x}(3)-463066$;

Constraints:

If we consider the production capacity as a key constraint in the production quantity of some products, temporarily ignoring the structure of demand for mentioned products on the market, the restrictions are:

$0 \leq \mathrm{x} 1 \leq 4400$

$0 \leq \mathrm{x} 2 \leq 2444$

$0 \leq \mathrm{x} 3 \leq 1100$

${ }^{* * *}$ Employees and raw material in the observed company are not of limiting character.

The Pareto front and values of the functions $f 1$ and Figure 1 are shown in Figure 4.

From the Pareto front diagram, it is evident that optimum solution for production quantity and profit maximization under given constraints is a set $[2312 ; 219 ; 944]$, where the maximum profit is $5,950,340 \mathrm{RSD}$ calculated as max ( $\mathrm{f} 1-\mathrm{f} 2)$.
After getting the optimum solution, the second step is Identify and analysis of risk sources for the observed optimum product program. In our case, we have focused on the internal resources only. Identification, evaluations, and determination of trend are shown in the table 2.

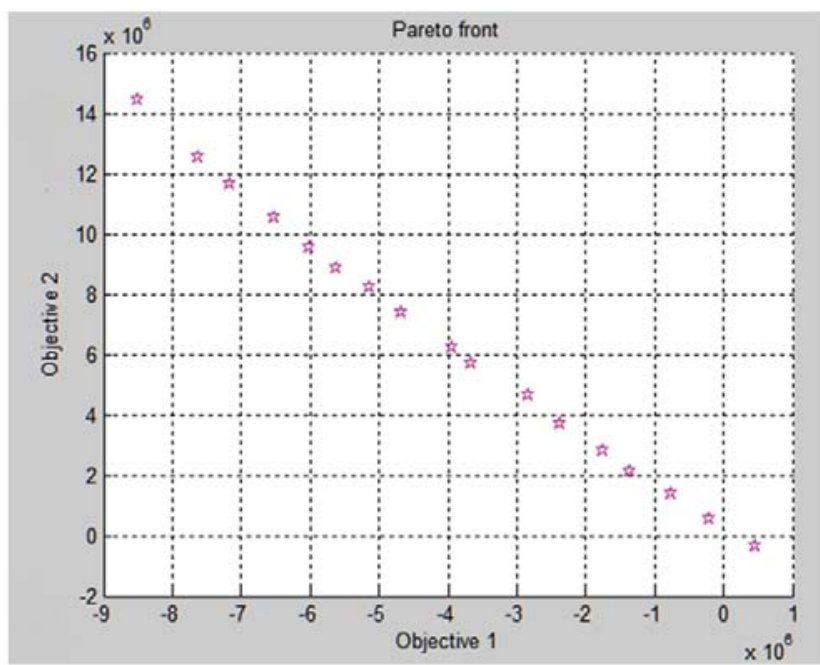

Figure 4: The Pareto front of optimum solution

This figure 5 shows a two-dimension risk map. The vertical axis represents loss likelihood and the horizontal axis represents loss impact. The four quarter panels stand for different combinations of likelihood and impact. 


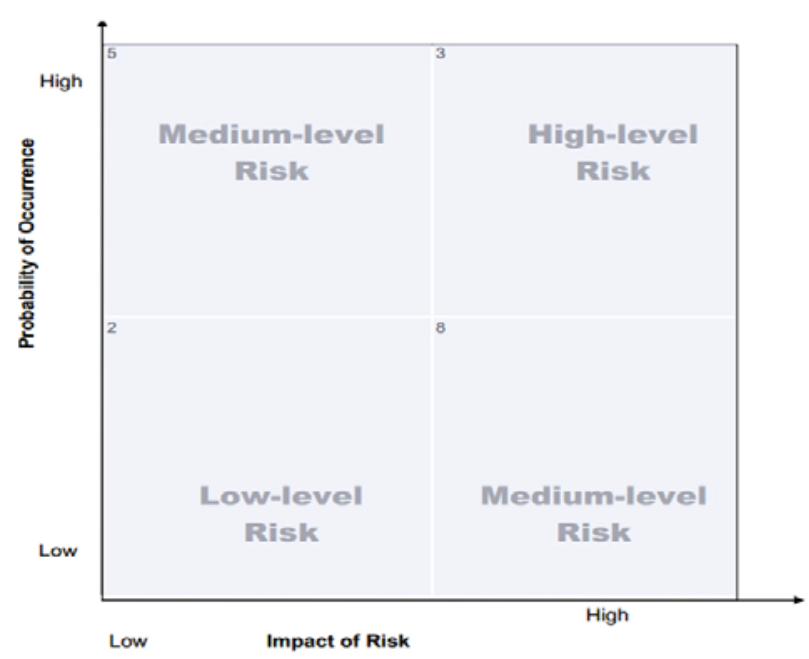

Figure 5: A Two-Dimensional Risk Map

Risk matrix indicates a small number of highrisky, a small number of low-risk risk sources, but the largest number risk sources with medium probability and consequences for business losses, namely:

$R_{i}=\left\{R_{\text {ligh }}, R_{\text {meditum },}, R_{\text {low }}\right\}=\{2,15,3\}$

Over all research results indicate that at these restrict conditions of production, there is comparatively high risk of production losses. Therefore, it is necessary to resolve our problem to find another optimal solution and repeat analysis until achieved an optimal production program.

\section{CONCLUSIONS}

A strong and cabable model of genatic algorithim combinding with risk mamagement mtrix is intrduced and developed to get optimal production program and increase the quality of decisions.

Applying genatic algorithm as a technique deals with huge conflect constrains to create one or altrenative optimal solusions. On ther hand, applying risk mamagement mtrix for choice of optimal production program reduces the risk of operating losses and affects the efficiency of management. Furthermore, qualitative aspects that are defined trough risk sources and by its identification and evaluation, more realistic production program evaluation can be taking into account. Integrated both of them, genetic algorithim and risk mamagement mtrix guide to optimal production program.

\section{REFERENCES}

1) C. McNair: Defining and Shaping the Future of Cost Management, Journal of Cost Management, Vol. 14, No. 5, 2000, pp. 28-32, ISSN 1092-8057.

2) Curović, D., Vasić, B., Popović, V., Curović, N.: Ekspertsko planiranje proizvodnje, (2008) Journal of Applied Engineering Science (Istraživanja i projektovanja u privredi), no. 20, p.49-57

3) Eckart, Z., Evolutionary Algorithms for Multiobjective Optimization: Methods and Applications. PhD thesis, Swiss Federal Institute of Technology (ETH), Zurich, Switzerland, November 1999.

4) Glover F., Kelly J.P., Laguna M., NewAdvances for Wedding Optimization and Simulation, Proceedings of the 1999 Winter Simulation Conference, 1999.

5) J. Fraser, B.J. Simskins: Enterprise risk management: Today's Leading Research and Best Practices for Tomorrow's Executives, John Wlley \& Sons, ISBN 978-0-470-49908-5, USA, 2010.

6) J. Sanchis, et al.:A new perspective on multiobjective optimization by enhanced normalized normal constraint method, Structural and Multidisciplinary Optimization, 2008, Vol. 36, No. 5, pp. 537-546, ISSN 1615-1488.

7) L. Chi-Ming, G.Mitsuo: An Effective DecisionBased Genetic Algorithm Approach to Multiobjective Portfolio Optimization Problem, Applied Mathematical Sciences, 2007, Vol. 1, No. 5, pp. $201-210$, ISSN 0066-5452.

8) Miettinen, K., Nonlinear multi-objective optimization. Springer, 1999.

9) N. Fafandjel, A. Zamarin, M. Hadjina: Shipyard production cost structure optimization model related to product type, International Journal of Production Reasearch, 2010, Vol. 48, No. 5, pp. 1479-1491, ISSN 0020-7543.

10) S. Utyuzhnikov, P. Fantini, M. Guenov: A method for generating a well- distributed Pareto set in nonlinear multi-objective optimization, Journal of Computational and Applied Mathematics, 2009, Vol. 223, No. 2, pp. 820-841, ISSN 0377-0427.

11) The CAS Enterprise Risk Management Committee: Overview of Enterprise Risk, Management,Casualty Actuarial Society Forum, 2003, Pages 99-164, ISSN 1046-6487

Paper sent to revision: 29.08.2012.

Paper ready for publication: 26.09.2012. 